\title{
THE PUPILLARY MEMBRANE IN PREMATURE INFANTS
}

\author{
BY \\ BRUNO GANS \\ From the Premature Baby Unit, Lewisham Hospital, London
}

(RECEIVED FOR PUBLICATION JANUARY 5, 1959)

The presence or absence of a pupillary membrane is a valuable sign of immaturity in infants born before term. This fact has been noted by Continental authors. As no reference to it could be found in British medical publications since the war the following brief account may be of use.

In the $13 \mathrm{~mm}$. embryo the annular vessel, a branch of the ophthalmic artery, forms an anastomotic ring round the rim of the developing optic cup. At the $17 \mathrm{~mm}$. stage buds arise from this annular vessel. These ultimately form a series of loops which lie on the anterior surface of the lens. In the 40 to $60 \mathrm{~mm}$. embryo there is an elaborate vascular network arranged in three tiers of arcades. After the fifth month of foetal life this network, the pupillary membrane, begins to atrophy. First the central tiers of arcades become progressively more attenuated and then disappear. As vascular involution proceeds the second arcade disappears behind the growing border of the iris. At term most of the loops have disappeared and only the first arcade remains. This forms a series of anastomotic vessels, the lesser circle of the iris (Duke-Elder, 1938). Minor remnants of the pupillary membrane are, of course, extremely common in full term infants (Seissiger, 1929) and indeed in the general population, particularly if their eyes are examined by means of a slit lamp.

The well-known difficulty of obtaining a good view of a premature infant's fundus oculi is due, in part, to the vessels of the pupillary membrane. On naked eye examination this structure is seen as a delicate blue-grey veil behind the pupillary aperture. After homatropin mydriasis the vessels constituting the membrane can be observed through the +20 lens of an ophthalmoscope. They form a spider's web which stands out black against the red retinal light reflex. To obtain a good view the examiner should hold the ophthalmoscope in his right hand and the infant's head in his left, using his left index finger to retract the upper lid. A nurse holds the baby's body and retracts the lower lid with her free index finger. Care must be taken not to let the cornea become dry by prolonged examination.
Fig. 1 shows the pupillary membrane of a 3-dayold infant weighing $2 \mathrm{lb} .2 \mathrm{oz}$. Figs. 2 and 3 represent the membrane of a baby weighing $2 \mathrm{lb} .12 \mathrm{oz}$. on the second and fourth day after birth. The marked reduction in the number and calibre of the vessels is noticeable. Figs. 4 to 8 illustrate the progressive changes taking place in the pupillary membrane of an infant observed from the third to the forty-first day of life, during which time her weight rose from $3 \mathrm{lb} .8 \mathrm{oz}$. to $5 \mathrm{lb} .1 \mathrm{oz}$.

During the last three years some 270 premature infants have been examined in the unit at Lewisham Hospital. From these observations it appears that the presence of a pupillary membrane, particularly if it is extensive, is a good though non-specific sign of immaturity. Schmöger (1955) found a clear-cut inverse relationship between the extent of the membrane and the length and weight of 302 premature infants whom he examined. It proved impossible to demonstrate such a simple relationship in the Lewisham material. Some small, though relatively mature, infants had no membrane or only one or two delicate threads. A similar finding is recorded by Huggert (1952) who found the membrane to be absent in two infants weighing less than $1,500 \mathrm{~g}$. and in five infants weighing between 1,600 and $1,700 \mathrm{~g}$. in a series of 66 premature infants, 11 of whom did have a pupillary membrane. In my experience, an easily seen membrane is present in the majority of immature babies, and almost always in those weighing less than $1,500 \mathrm{~g}$. The number and size of the vessels closely parallels the degree of immaturity, and an extensive network appears to be a more reliable prognostic index than the baby's gestation period, its weight or the degree of its hypothermia. It closely agrees with one's clinical impression of the infant's viability.

The rate of vascular obliteration and disappearance of the membrane also follows closely the infant's general progress. Schmöger (1955) states that the membrane disappears within a few days of birth, almost always at the end of the first week, and at the latest in the second week. In my experience 


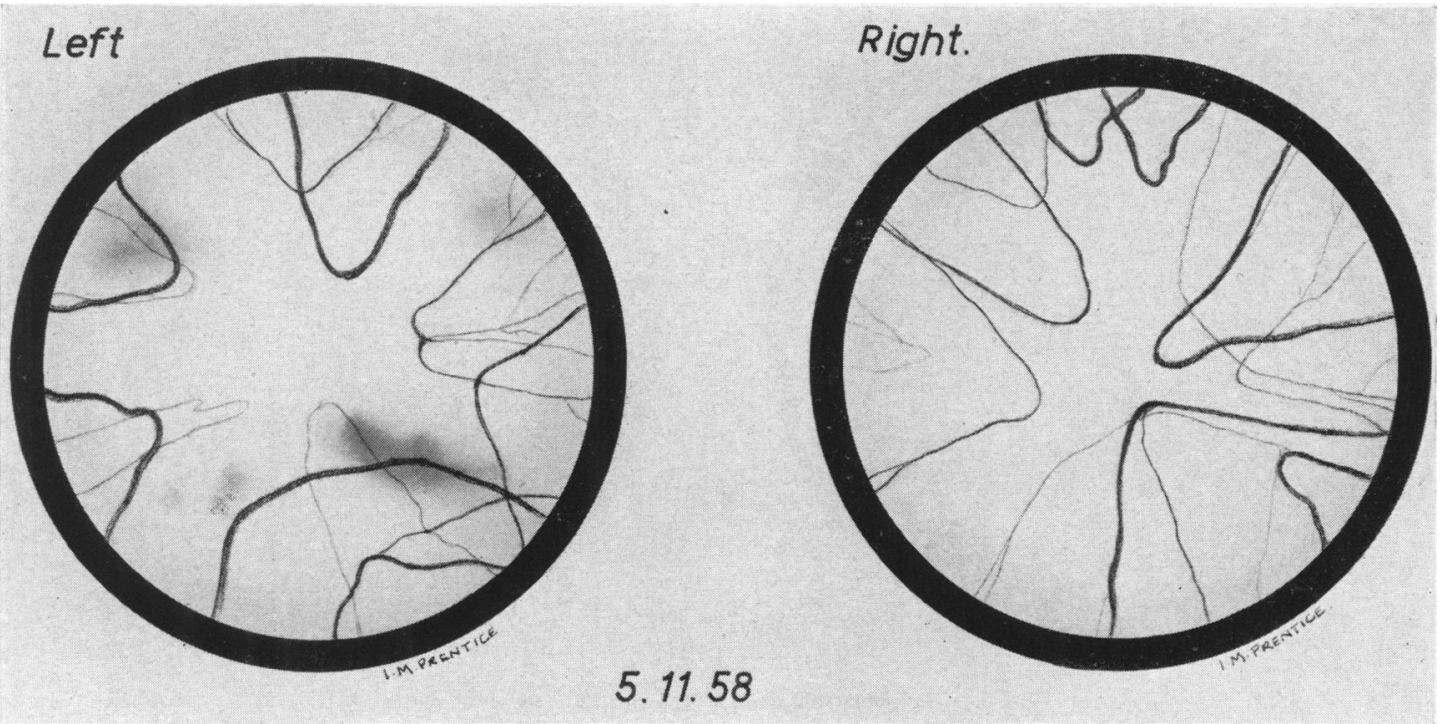

Fig. 1.-Pupillary membrane of 3-day-old infant weighing $2 \mathrm{lb} .2 \mathrm{oz}$.

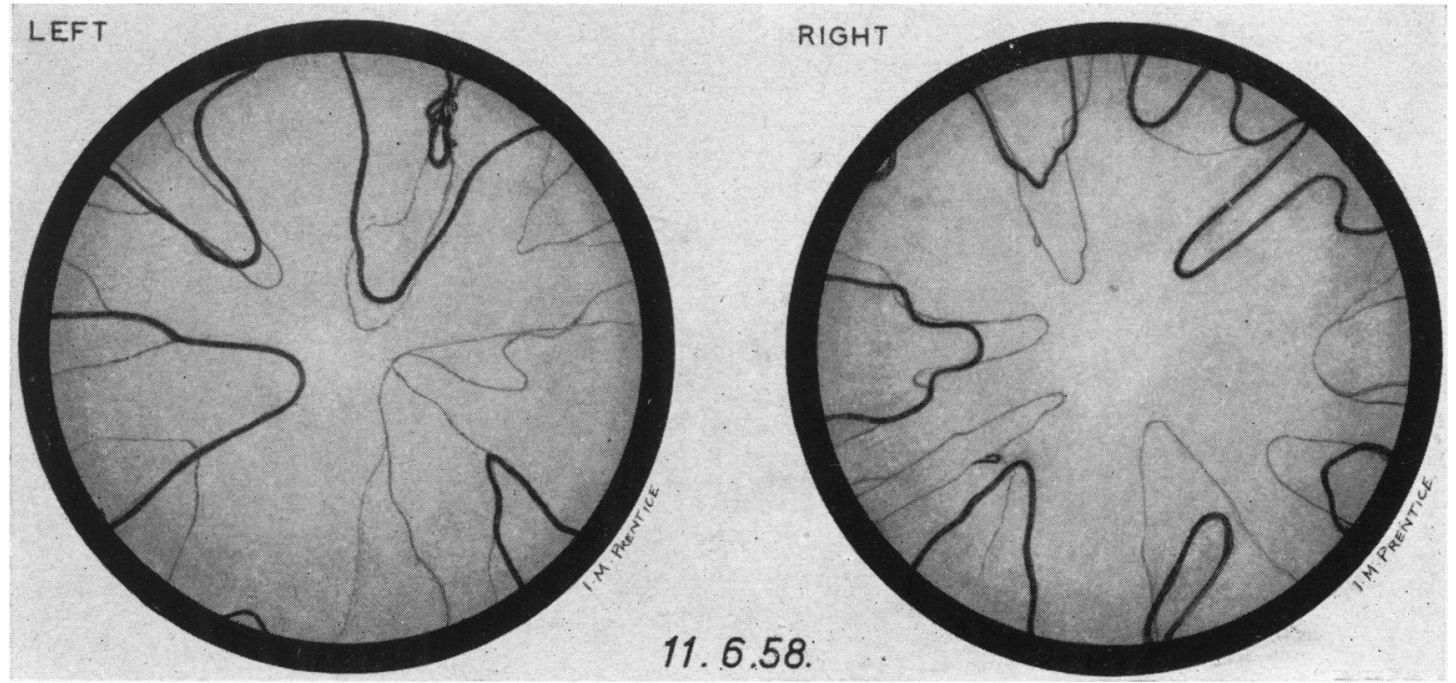

FIG. 2.-Pupillary membrane of 2-day-old baby weighing $2 \mathrm{lb} .12 \mathrm{oz}$. 

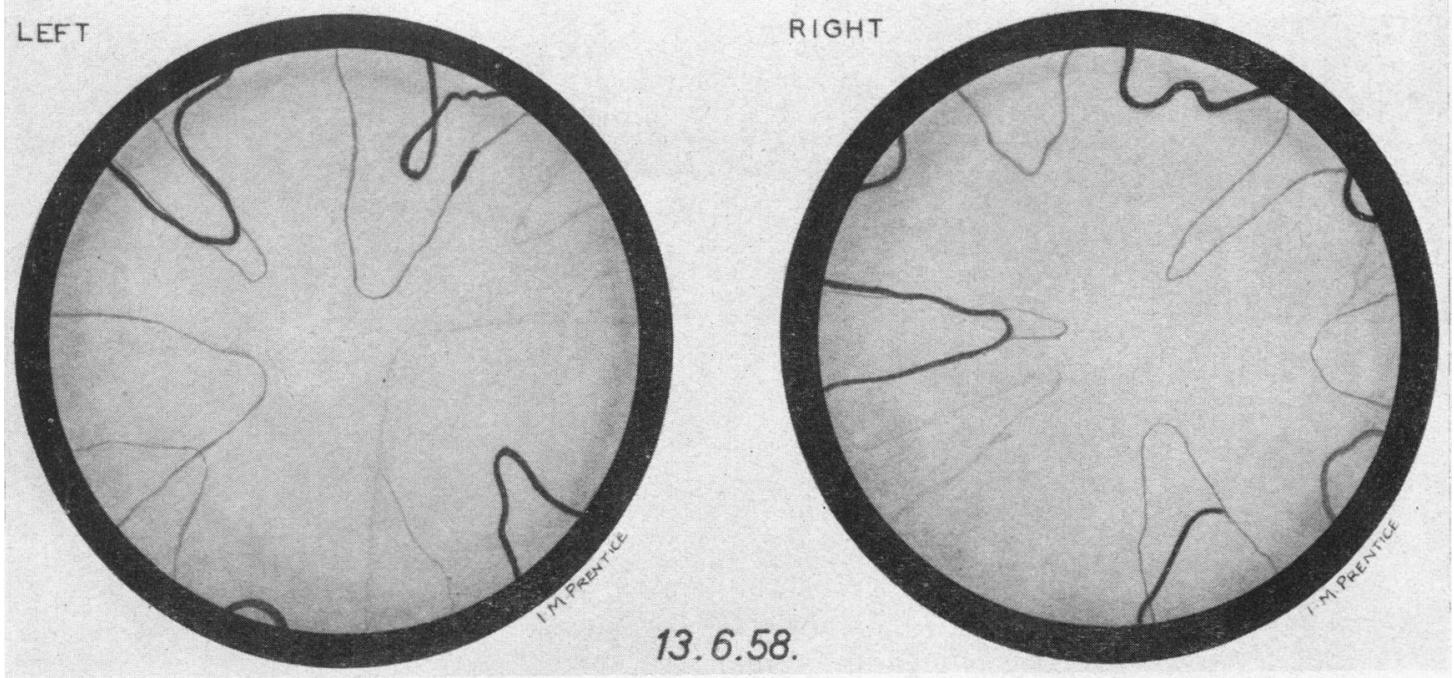

Fig. 3.-The same child as in Fig. 2 on fourth day after birth

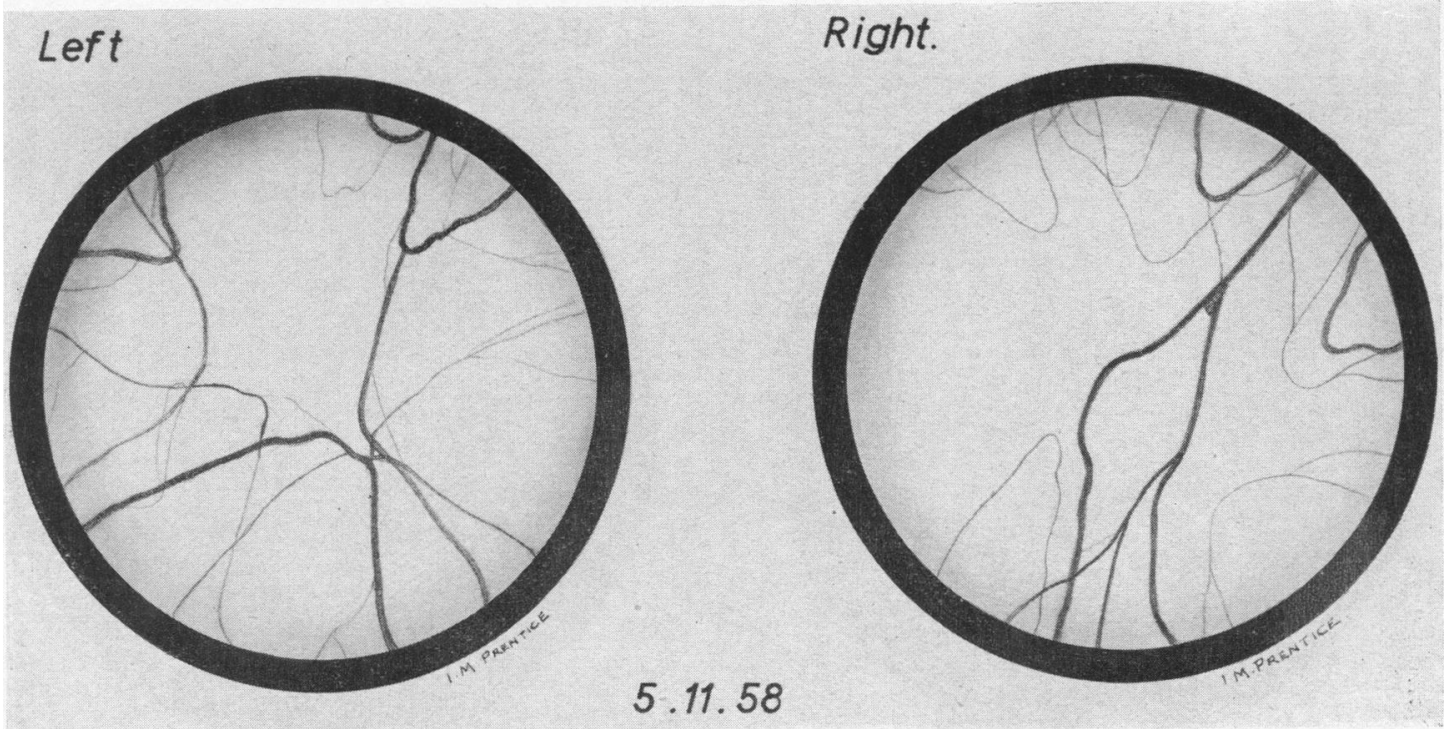

FIGS. 4-8.-Progressive changes in pupillary membrane of infant observed from 3 to 41 days old, during which time her weight increased from $3 \mathrm{lb} .8 \mathrm{oz}$. to $5 \mathrm{lb} .1 \mathrm{oz}$. 

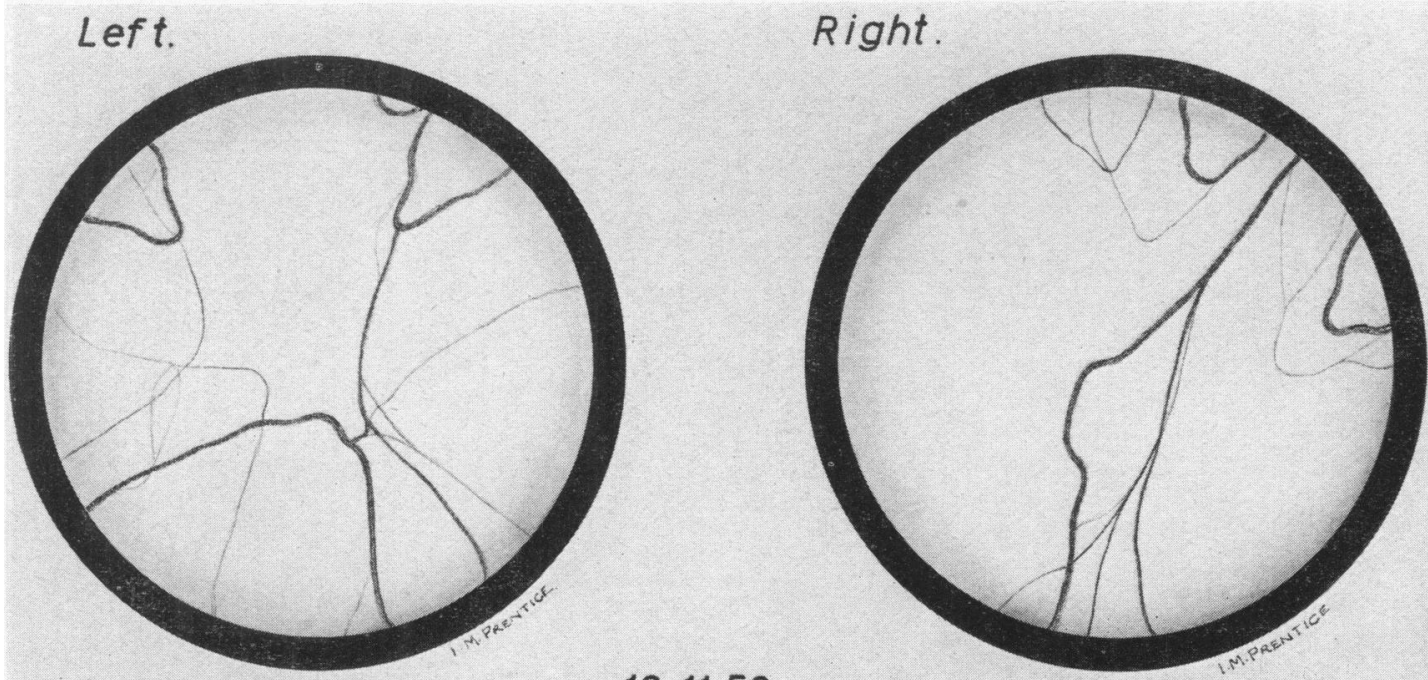

12. 11.58

FIG. 5.

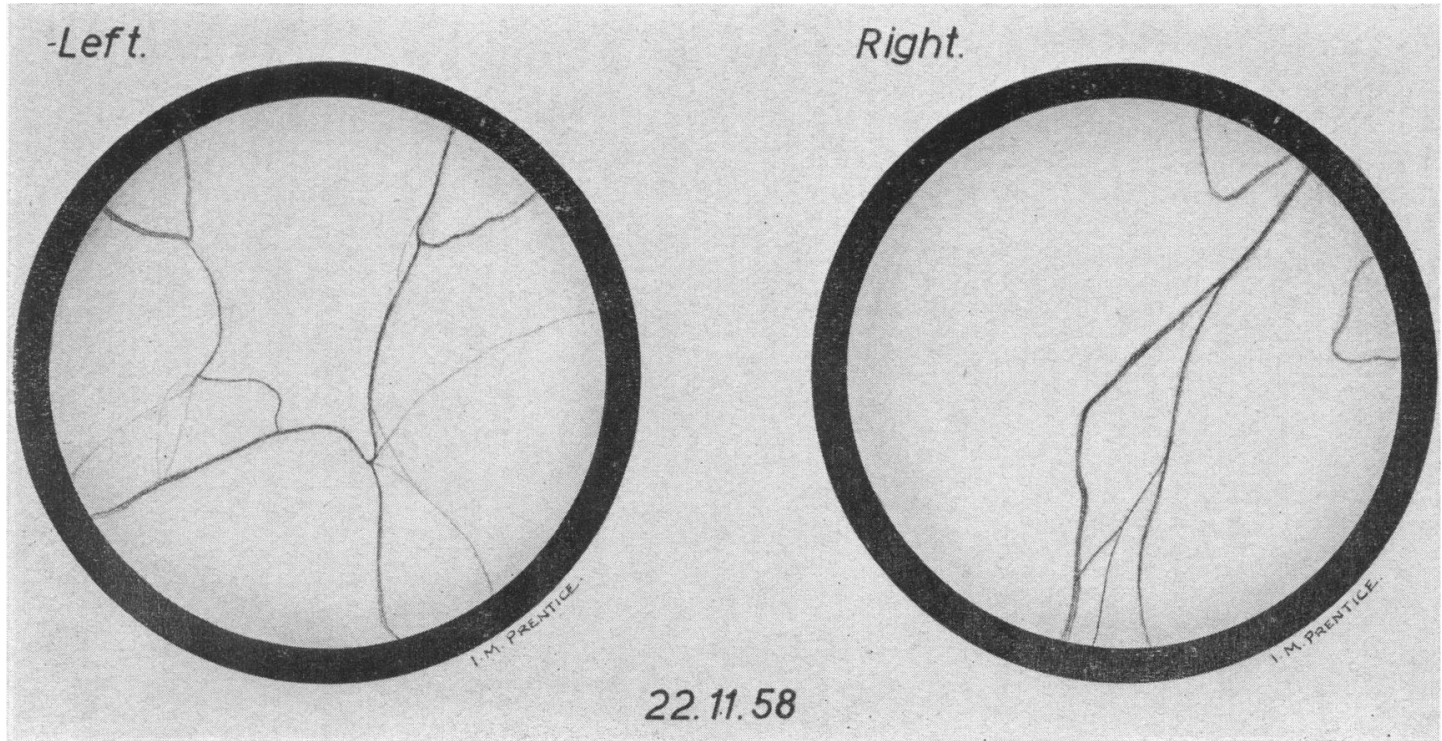

Fig. 6

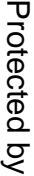




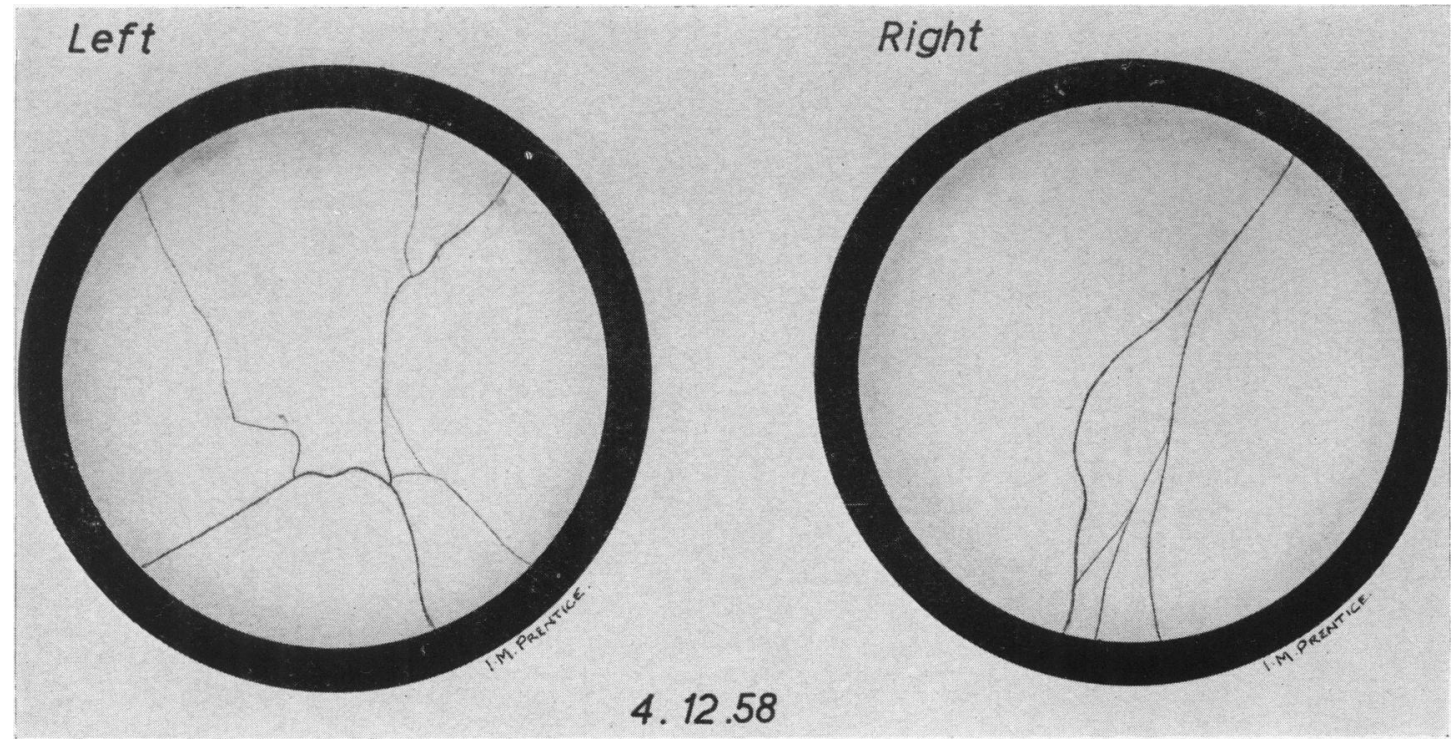

FIG. 7.

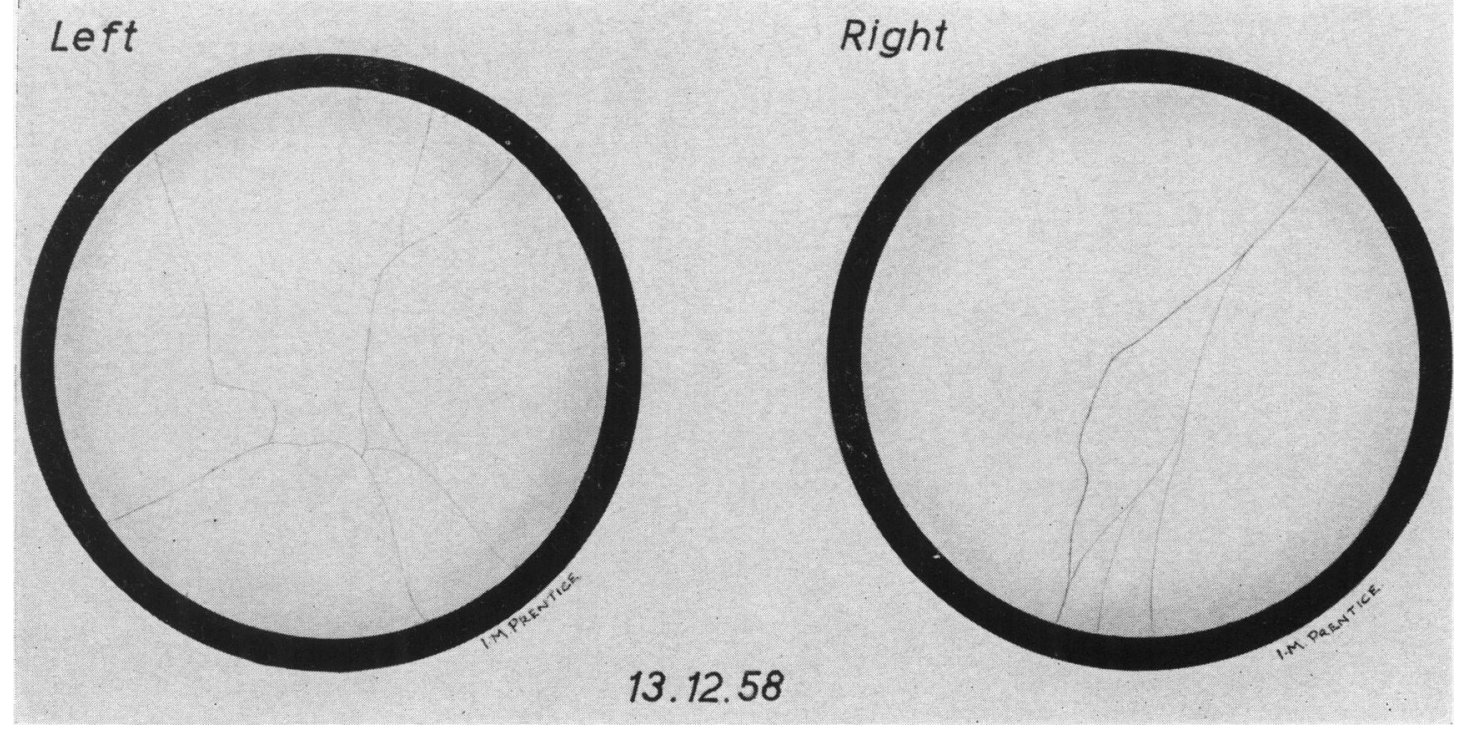

FIG. 8. 
no hard and fast rule can be made about the time taken for the vessels to disappear. This finding would be expected if the assumption is correct that the pupillary membrane disappears pari passu with the infant's progressive maturation. Most infants are discharged from the unit when they weigh $6 \mathrm{lb}$. and in none of those discharged was a persistent pupillary membrane found. No doubt slit lamp examination would have revealed remnants, invisible through a simple lens, in the majority. In 104 children of originally low birth weight $(1,020$ to 2,500 g.), Wagner (1957) found no case of persistent membrane when these children were examined at the ages of 3 to 5 years.

\section{Summary}

The presence and extent of the pupillary membrane is a valuable index of immaturity in premature infants.

\section{REFERENCES}

Duke-Elder, W. S. (1938). Textbook of Ophthalmology, Vol. 1 (2nd impression). Kimpton, London.

Huggert, A. (1952). Acta paediat. (Uppsala), 41, 463.

Schmöger, R. (1955). Kinderärztl. Prax., 23, 433.

Schmöger, R. (1955). Kinderärztl. Prax., 23, 433.

Weissiger, J. (1929). Arch. Augenheilk., 100-101, 302. 